\title{
Tecnologias e a crise da democracia: desafios à prática e ao ensino do Jornalismo no Brasil
}

\section{Technologies and crisis of democracy: challenges in practicing and teaching of journalism in Brazil}

Recibido: $15 / 07 / 2019$

Aceptado: 27/10/2019

Publicado: 05/12/2019
Nemézio Amaral Filho nemezio.filho@gmail.com Universidade do Estado do Rio de Janeiro (Brasil)

Resumen: El propósito de este artículo es analizar brevemente el modelo económico-ideológico del mercado de la comunicación en Brasil, destacando su influencia en el escenario político nacional actual. Luego abordamos las tensiones causadas por los flujos, y no un elemento particular, de las nuevas tecnologías de comunicación e información en la crisis de la autoridad enunciativa del periodismo; al mismo tiempo, reforzaremos la importancia de esta oficina para el mantenimiento de la democracia en crisis en el país en particular, y en Occidente en general, mediante el mapeo de estrategias tecnológicas adoptadas por empresas y profesionales. Finalmente, a la luz de investigaciones similares, concluiremos con el diseño de las pautas curriculares de lo que entendemos debería guiar los debates sobre la transición de la educación periodística (cada vez más transdisciplinaria, recurriendo a nuevos apoyos tecnológicos y el refuerzo necesario del fortalecimiento humanista) en las universidades brasileñas. Más tarde, se presentan sugerencias para la inclusión de empresas de medios (grandes, medianas, pequeñas y extranjeras en suelo nacional), ONG y la sociedad civil en el debate sobre el periodismo que queremos en medio de la crisis de la democracia. 
Palabras clave: Periodismo, Tecnología, Regulación, Enseñanza, Democracia, Crisis.

Abstract: The purpose of this article is to briefly analyze the economic-ideological model of the communication market in Brazil, highlighting its influence on the current national political scene. Then we address the tensions caused by the flows, and not a particular element, of the new communication and information technologies in the crisis of the enunciative authority of journalism; At the same time, we will reinforce the importance of this office for the maintenance of democracy in crisis in the country in particular, and in the West in general, through the mapping of technological strategies adopted by companies and professionals. Finally, in the light of similar research, we will conclude with the design of the curricular guidelines of what we understand should guide the debates on the transition of journalistic education (increasingly transdisciplinary, resorting to new technological support and the necessary reinforcement of humanistic strengthening) in the Brazilian universities. Later, suggestions are presented for the inclusion of media companies (large, medium, small and foreign on national soil), NGOs and civil society in the debate about journalism that we want in the midst of the democracy crisis.

Key words: Journalism, Technology, Regulation, Teaching, Democracy, Crisis.

\section{Introdução}

A comunicação social, e o jornalismo em particular, em todo o mundo sob influência ocidental, atravessa mais uma crise paradigmática. De um lado, os avanços da tecnologia exercem profunda pressão sobre a forma como o jornalismo é realizado, tanto em pequenos empreendimentos quanto na grande mídia corporativa; de outro, derivando das possibilidades que essa mesma tecnologia proporciona, o ofício vem perdendo credibilidade em ambientes cada vez mais autoritários (física e discursivamente), no Brasil e no exterior, não por acaso, antes da eleição do atual governo brasileiro, de fortes matizes autoritárias, $83 \%$ dos brasileiros já se diziam insatisfeitos com a democracia (Dias, 2019). 
O Brasil vê a crise da autoridade enunciativa do jornalismo deslocar-se do proscênio da formulação de sentidos sociais e a assunção de novas vozes pelas ferramentas digitais on-line. Mas o descrédito que a mídia oligopolizada no Brasil e mainstream nos EUA (muito menos concentrada que a brasileira), por exemplo, têm enfrentado faz par com a crise de credibilidade de outras instituições democráticas. Por exemplo, em 2019, a $19^{a}$ edição da pesquisa anual de confiança e credibilidade feita pela Edelman Trust Barometer mostra que, no Brasil, o índice de confiança no governo, em relação a 2018, subiu 10 pontos (chegando a $28 \%$ ) e, na mídia, caiu 2 (chegando a 41\%). Ambos seguem abaixo do nível de neutralidade no julgamento da população. $\mathrm{O}$ índice vai de 0 a 100 pontos (Edelman, 2019). Isso não parece ser apenas o resultado do desenvolvimento tecnológico, ainda que não se pretenda aqui negar nem por um momento sua força disruptiva (segundo a mesma pesquisa, 64\% dos brasileiros têm medo de perder o emprego para a automação e outras inovações, contra 55\% no resto do mundo, em média).

Soam-nos, entretanto, questionáveis as análises que propõem soluções para um novo modelo de fazer jornalismo centradas apenas no (importantíssimo) saber tecnológico. O sentido sociocultural, ou seja, seu papel idealizado pela população na democracia, demonstra ser mais afetado pela política tradicional do que pela tecnologia em si. Certo é, porém, que essa mesma velha política foi subitamente ressignificada com o uso massivo das possibilidades enunciativas da comunicação on-line. Por outro lado, isso coloca o jornalismo hegemônico brasileiro no cerne da crise institucional, ética e moral que atravessam as instituições no país; e aqui não nos referimos apenas à figura de governos. A presença dos interesses privados sobre o público (empresas de mídia jornalística incluídas), como denuncia Souza (2017), estende-se para além da narrativa do patrimonialismo, do "combate à corrupção" e do Estado como responsável pelo atraso e pelas mazelas nacionais.

Essa crítica se dá em observância à História: a imprensa chegou tardiamente ao Brasil, em 1808, com a fuga da família real portuguesa da fúria de Napoleão. Ou seja, o que viríamos a chamar de mídia hegemônica brasileira é inaugurada na então colônia - quase toda povoada por analfabetos -, atrelada ao poder tradicional, e não por força do novo, representado pela burguesia contra as oligarquias, como ocorreu no continente europeu (Werneck Sodré, 1994; Briggs \& Burke, 2006) A empresa jornalística se deslocaria, dessa forma, de um poder central a outro, representado pelas oligarquias num primeiro 
momento e, depois, enfim, pela ascensão da burguesia industrial. Note-se aí o interesse de grupos economicamente poderosos a reger quais e como determinadas questões sociais deveriam ser comunicadas.

Assim, hoje, falar de regulamentação dos meios de comunicação no Brasil é a certeza de ter contra si as baterias da mídia hegemônica carregadas de pós-verdades acerca da confusão proposital entre "liberdade de expressão" e "liberdade de imprensa" (Lima, 2012), obnubilando o fato de que o segundo conjunto está dentro do primeiro, ou seja, este não é do tamanho daquele. Certamente os porta-vozes das empresas concentradoras não ousariam chamar os EUA de "bolivarianos" por terem regulamentado o próprio mercado de mídia - de resto, "mercado" como qualquer outro, portanto, passível de regulamentação. E os EUA fizeram isso em 1934. Ao defender um modelo de TV pública para o Brasil, Bucci (2010, p. 9) lembra do porquê dessa opção dos norte-americanos:

[...] embora a matriz da radiodifusão [nos EUA] tenha se baseado muito mais no modelo comercial, deu-se a adoção de regras públicas bem assertivas, com o objetivo de proteger os mesmos valores. Esse dado normalmente não é percebido por quem se interessa pela história das emissoras públicas, mas também nos Estados Unidos, ainda que o modelo tenha sido privado e comercial, o Estado implantou regras e regulações de ordem pública para impedir, no linguajar do liberalismo, a captura (na semântica da socialdemocracia o termo seria "colonização") da agenda pública de debates por interesses privilegiados.

Foi assim que surgiu a agência reguladora FCC (Federal Communications Commission), em 1934, para impedir formas sutis ou ostensivas de monopólio nos meios de comunicação. Os objetivos centrais da FCC são garantir, no plano político, a pluralidade de vozes e, no plano econômico, a concorrência saudável entre as diversas empresas do setor. As pessoas se perguntam por que, por exemplo, nos Estados Unidos, se firmaram três redes nacionais de televisão aberta (NBC, $\mathrm{CBS}$ e $\mathrm{ABC}$ ). A resposta é muito simples: elas são três porque a lei, por meio da $\mathrm{FCC}$, assim obrigou. $\mathrm{O}$ mercado realizava, pois, um projeto público. Com base nesses e outros propósitos, a FCC vem inibindo oligopólios e monopólios, com as adaptações que os tempos requerem, conforme as mudanças de padrão tecnológico (grifos nossos).

O Brasil, por seu turno, preferiu traçar rumos distintos daquele modelo do mais ao norte e da tradição europeia. Para sermos mais precisos social e his- 
toricamente, a opção pela concentração midiática tem sincronia com a limitação de perspectiva das elites latino-americanas. Como explica (Mauersberger, 2016. pp. 4-5):

A estrutura dos mercados de mídia e sua regulamentação refletem em muitos aspectos as marcantes desigualdades sociais pelas quais a América Latina ainda é famosa. O Estado tem historicamente assumido um papel indireto no desenvolvimento da radiodifusão, que sempre foi deixado para a iniciativa privada. Consequentemente, a radiodifusão é entendida fundamentalmente como uma empresa comercial; mesmo quando o Estado assumia o controle (como fez na Argentina há vários anos), as estações continuavam a ser operadas sob modelo comercial. Propriedade privada, falta de regulação forte, e às vezes também subsídios direcionados para o fortalecimento de poderosos atores nacionais levaram a processos de concentração com pouquíssimas empresas dominando o setor. Em alguns países, uma corporação assume uma posição quase monopolista. Esses conglomerados são frequentemente ativos em diferentes setores de mídia ao mesmo tempo (televisão, TV a cabo, rádio, jornal, internet) e ligados a outros setores da indústria ou de serviços, seja através de ações diretas, acordos de publicidade ou vínculos pessoais.

\section{Mídia como "partido político"}

Fiel a essa tradição, a mídia hegemônica brasileira, quando tem seus interesses ameaçados ou ao lutar pela ampliação do próprio poder político (não oficialmente como partido), nas palavras do sociólogo Fernando Haddad, "funcionam como monopólio do ponto de vista político" (Haddad, 2017).

Os grandes grupos de comunicação são geridos por famílias que pensam da mesma forma e têm a mesma agenda para o País, com variações mínimas. Em momentos cruciais de nossa história, como em 1964 e 2016, atuam em bloco (Haddad, 2017).

Rapidamente, poder-se-ia argumentar que as palavras de Haddad estão carregadas de rancor ideológico e, assim, deveriam ser relativizadas, principalmente porque os desdobramentos da ruptura institucional de 2016 com a deposição de Dilma Rousseff, de cujo governo Haddad foi ministro Educação e posteriormente candidato derrotado à presidência do País, ainda estão em curso: Haddad teve que substituir Luiz Inácio Lula da Silva, que liderava 
literalmente todas as pesquisas de intenção de voto, mas foi impedido de participar das eleições por força de uma questionável condenação por corrupção dada pelo mesmo juiz (Sérgio Moro) que abandonaria a toga e assumiria o posto de ministro da Justiça no governo do principal adversário das esquerdas, o ultraconservador Jair Bolsonaro.

As ações da hoje criticada Operação Lava Jato, crítica que recrudesceu depois dos vazamentos de conversas impróprias entre procuradores e destes com o então juiz Sérgio Moro, como revelou o site The Intercept Brasil (Greenwald, Reed \& Demori, 2019), mostrando os alvos seletivos dos agentes públicos, principalmente, Lula da Silva, também foram midiaticamente construídas. A História, então, daria razão à análise de Haddad? Vejamos.

A radiodifusão crescia velozmente no Brasil no início da década de 1960. Sua importância foi percebida como fundamental, o que levou à criação do Código Brasileiro de Telecomunicações, que estabelecera, por exemplo, as regras para concessão e renovação de licenças. O processo de criação e modificação dessa lei ( $\mathrm{n}^{\circ} 4.117$, de 27 de agosto de 1962), ainda a base do modelo vigente no País, parece ser um exemplo do caráter constitutivo da mídia hegemônica brasileira e da capacidade de articulação e de intervenção do setor privado sobre o público. O então presidente João Goulart sancionou a lei com 52 vetos, todos em defesa do interesse público e para limitar o período de concessão de licenças às empresas de radiodifusão. Mas, atesta Mauersberger (2016, p. 151, tradução nossa):

[...] Quando o Congresso se reuniu em 26 de novembro de 1962 para se contrapor aos vetos presidenciais, teve de recuar à noite por falta de quórum. Na manhã seguinte, quando o Congresso se reuniu novamente, a Associação Brasileira de Estações de Rádio e Televisão (ABERT) anunciou sua fundação. A nova entidade para emissoras comerciais tornou explícita sua rejeição às posições de Goulart. Seguindo as recomendações da ABERT, naquele mesmo dia e no próximo, o Congresso derrubou um a um cada veto presidencial.

Note-se que essa ação "como partido político" tem coerência histórica do ponto de vista discursivo, principalmente quando nos atemos ao período recente em que as possibilidades de fala de atores sem acesso aos meios tradicionais de comunicação eram bem mais limitadas. Décadas mais à frente, já no ocaso 
do golpe militar, durante o qual o apoio mútuo entre a ditadura e empresas de radiodifusão foi explícito, a exigência por garantias constitucionais que assegurassem o direito à comunicação bateu às portas da Assembleia Constituinte. Em 1984, a Frente Nacional de Lutas por Políticas Democráticas de Comunicação, erguida por jornalistas, ativistas e sindicalistas, entregou ao Congresso milhares de assinaturas, propondo um capítulo sobre comunicação social na Constituição. Essas demandas foram combatidas pelas empresas de mídia. Ainda assim, o resultado foi um capítulo de cinco artigos que abordam, de maneira geral, muitas das principais reivindicações do movimento pró-democratização. A Constituição de 1988 ainda é uma referência central nas lutas de hoje pela democratização da mídia (idem). Não por acaso, diferentemente das seis outras que a antecederam, foi a primeira a destinar todo um capítulo à temática.

De seu lado, os jornais impressos, que em sua maioria deram apoio ao golpe militar de 1964, escreviam editoriais sobre os "excessos" que os constituintes desenhavam para a futura Carta Maior: o Jornal do Brasil protestou contra as 40 horas de trabalho a ser prevista pela Constituição, O Globo era contra o aumento da licença remunerada à gestante, O Estado de São Paulo também criticava as 40 horas de trabalho para todos, a Folha de S. Paulo bradava contra o direito de greve etc (IPEA, 2010).

O que move o discurso da mídia hegemônica hoje (privatização, terceirização, limitação dos gastos sociais do governo por planejadas duas décadas, ataque ao ensino gratuito e aos servidores públicos) nem sequer é original: segue um modelo construído nos EUA nos anos 1980, com o início do desmantelamento do aparelho regulatório, e depois espalhado à sua zona de influência. A receita é simples: debilita-se o Estado e acuam-se os "vilões" de sempre - minorias e agentes públicos; no último caso, principalmente aqueles que se voltam ao saber. Como denuncia Chomsky (2017, p. 79), com palavras que soam familiares a muitos brasileiros:

Os professores constituem um alvo particularmente propício, como parte do esforço deliberado para destruir o sistema público de educação, desde a pré-escola até as universidades, por meio da privatização - mais uma vez, uma política que é boa para os ricos, mas um desastre para a população, bem como para a saúde de longo prazo da economia, embora seja mais uma das externalidades que são postas de lado, contanto que prevaleçam os princípios do mercado. 
Para o prosseguimento de nossa argumentação, é importante entender que a crise na democracia que hoje o país enfrenta (pela ordem: o impeachment para muitos, sem crime - de uma presidente democraticamente eleita, a questionável prisão do candidato líder das pesquisas, o ex-presidente Luiz Inácio Lula da Silva, e a tomada do poder pela extrema direita) não teria prosperado tão facilmente com uma mídia fora de um mercado arcaicamente oligopolista, agindo como "partido político". E isso é amalgamado pelo mercado de comunicação, como constata Sodré (2014, p. 55):

Para começar, capitalismo financeiro e comunicação constituem hoje, no mundo globalizado, um par indissolúvel. O capitalismo contemporâneo é ao mesmo tempo financeiro e midiático: financeirização e mídia são as duas faces de uma moeda chamada sociedade avançada, essa mesma a que se vem apondo o prefixo "pós" (pós-industrialismo, pós-modernidade etc.).

Em sua análise, Sodré identifica o que chama de um "novo modo de ser da riqueza", o que requer "o concurso historicamente inédito da comunicação e da informação", uma vez que a grande mídia funciona como "biombo ideológico da financeirização" (p. 56).

Ciente dos danos à democracia que um mercado de mídia hiperconcentrado como o brasileiro provoca, em 2010, o jurista Fabio Konder Comparato ajuizou uma Ação Direta de Inconstitucionalidade por Omissão no Supremo Tribunal Federal, STF (Comparato, 2010). Argumentava que era preciso regulamentar, entre outros, o artigo 220 da Constituição de 1988, que veda o monopólio direto e indireto dos meios de comunicação no Brasil. Sua ação espera atenção do STF há 9 anos. A ausência de regulamentação do dispositivo constitucional já soma 31 anos. Não por coincidência, muitos TVs retransmissoras dos conglomerados de mídia estão nas mãos de políticos conservadores, que, por óbvio, não têm interesse na democratização dos meios.

O mercado da grande mídia nas mãos de poucas pessoas facilita acordos tácitos ou explícitos quando há interesses em comum dos detentores desse setor. O escândalo dos vazamentos dos diálogos de procuradores da República contra determinados personagens da política e da economia nacionais, recentemente denunciado pelo site The Intercept Brasil (Greenwald \& Neves, 2019) é um exemplo de como a mídia brasileira intervém nos rumos sociais para além dos limites do seu negócio. A sequência de matérias mostrando as 
práticas antiéticas, ilegais e, em muitos casos, em conluio com o "partido da grande mídia" parecem dar razão à pesada crítica dos juristas Proner \& Strozake (2017) escrita antes mesmo do escândalo dos vazamentos.

Importa denunciar o papel da mídia televisiva nesse processo penal de exceção. A sentença proferida contra Luiz Inácio Lula da Silva e exemplo claro do esforço levado a cabo por parte da imprensa comprometida com interesses econômicos, aliada à noção do direito penal do inimigo, que se permite relativizar princípios basilares do Direito Constitucional, Direito Penal e do Processo Penal.

A mídia hegemônica, tanto televisiva como escrita, com a pretensão de reforçar e justificar o uso de métodos excepcionais no sistema de Justiça, com o fim de convencer a opinião pública sobre a necessidade de uma "justiça justicialista" contra um "inimigo comum", ataca o cerne da democracia.

Para essa mídia concentrada nas mãos de poucas famílias proprietárias, claramente compromissada com setores econômicos dentro e fora o Brasil, a corrupção é tratada como sendo método adotado por políticos e partidos escolhidos seletivamente, normalmente do campo da esquerda, evidenciando a aliança de setores da mídia com outros políticos visando as eleições e a governabilidade para atender aos interesses privados.

Há que se repudiar o jornalismo praticado por empresas de telecomunicação e jornalismo que, igualmente corrompidas e corruptoras, mentem, enganam, violam o direito à informação e a verdade dos fatos, sendo corresponsáveis pela instabilidade institucional e política do Brasil, coniventes com o aumento do autoritarismo, com os retrocessos sociais e com a violência, não sendo desarrazoado falar em corrupção da mídia no Brasil (grifos nossos).

\section{Tecnologia: desafios ao ensino de Jornalismo e à democracia}

Entretanto, a mídia corporativa oligopolizada teve flancos abertos pela tecnologia. A ameaça de desqualificação e absorção da atividade jornalística por plataformas, como Facebook (e as demais que foram compradas por ele como o Instagram, o WhatsApp e o Periscope) e o YouTube, está sendo enfrentada com a união das empresas jornalísticas e por pesquisadores acadêmicos de mídia (Bell \& Owen, 2017) internacionalmente. Essa união tem provado que há um risco real às democracias quando plataformas sociais digitais, cuja principal preocupação é o entretenimento e o maior número possível de pessoas conectadas a qualquer custo, provocam a disfunção da atividade jornalística, como mostram a propagação de fake news e/ou as informações 
enviesadas que levem a polarizações ideológicas em sites apócrifos, mas que geram muito tráfego: sites são remunerados pelos sistemas automatizados de publicidade. Mas nem sempre quando o objetivo das páginas de fake news é "só" dinheiro, pois também podem ser remuneradas por quem tem interesse político ou ideológico nas "notícias". Esse poder abrupto e assombroso proporcionado pela tecnologia não será disciplinado pela autorregulação do setor, cada vez mais concentrado, como já entenderam governos europeus, no caso do Google (Globo.com, 2019), mas pela força do Estado no exercício legal da democracia.

Academia e empresas de comunicação jornalísticas estão, assim, nos EUA por exemplo, construindo argumentos acadêmicos, técnicos, políticos e fundamentalmente morais para impedir o crescente poder das redes sociais em sua perigosa imbricação com o jornalismo. Mas isso também só é possível naquele país porque, como vimos, os EUA já regulamentaram sua mídia tradicional desde os anos 1930. Uma outra regulação agora é necessária porque estamos diante de uma "outra mídia". Os donos das empresas oligopolizadas de mídia no Brasil entendem isso e, apesar dos ataques das redes sociais a nacos no mercado, esquivam-se do debate. Como o Google, o Facebook sabe que em breve terá de abrir mão de parte da margem de lucro que aufere, o lucro líquido da empresa foi de US\$ 15,9 bilhões em 2017, alta de 56\% em relação ao ano anterior (UOL, 2018) se quiser continuar existindo, submetendo-se às leis dos países desenvolvidos, após o necessário debate social e nas casas legislativas. No Brasil, essa "segunda regulação" não é possível (ou não deveria ser) sem a primeira.

Quando se fala em regulação, não se admite redução de margem de lucro, volta-se ao discurso mequetrefe da "empresa nacional" contra redes sociais e marcas jornalísticas internacionais (que ameaçam o discurso único) e da censura à liberdade de expressão. E isso nada tem a ver com o uso propositadamente deturpado no Brasil da palavra "ideologia", ou chamaremos EUA, Alemanha, França, Inglaterra, Japão de potenciais socialistas por terem rígidos sistemas regulatório do mercado de mídia, e nem mesmo com o Direito (a regulação é prevista, como vimos, em dispositivo constitucional há 30 anos). Essa atitude de donos do que é público (o espectro eletromagnético no caso das TVs e rádios) e de tudo o que é privado lembra mais o método de desenvolvimento escravocrata brasileiro (Souza, 2017) e deve ser analisado mais pela História, pela Sociologia e pela Antropologia, disciplinas fundamentais 
do saber que, de maneira mais ou menos explícita, vêm sendo atacadas desde o governo de Michel Temer, que sucedeu o de Rousseff após o impeachment, até o atual, de extrema-direita.

Está cada vez mais difícil, porém, manter a fuga do debate da regulamentação: de propriedade do grupo Globo, o maior conglomerado de mídia do Brasil, o jornal Valor Econômico postou matéria sobre os avanços da indústria de fake news por meio do uso deletério da inteligência artificial. $O$ jornal considerou, como defende Zuckerberg que, para as plataformas sociais (as chamadas "empresas de tecnologia"), o tema da regulamentação é "inescapável" (Rydlewski, 2019). Nenhuma palavra do Valor sobre o mercado oligopolizado da mídia tradicional brasileira.

Chega-se, assim, ao cerne de nossa discussão: como projetar o ensino de Jornalismo norteado pelo futuro do mercado brasileiro, extremamente concentrado, com a (ainda) reduzida possiblidade de inserção de novos entrantes/ou da opinião efetiva de profissionais (jornalistas, operadores do direito, sociedade civil etc) na regulação do negócio em meio à crise de credibilidade da mídia corporativa? Qual o peso das novas tecnologias na transição do fazer jornalístico e na remodelagem do mercado oligopolizado brasileiro? Com isso, tem-se a pergunta incontornável ao mundo acadêmico (e não apenas aos docentes de Jornalismo tal a relevância à democracia do tema em questão): qual diretriz curricular deveria ser adotada nos cursos superiores de Jornalismo ante a nova realidade social e de mercado?

Em primeiro lugar, parece-nos evidente que é preciso ter uma discussão aberta e franca com os novos pretendentes à profissão em mutação. Em 2017, na pesquisa intitulada The future of journalism in a networked society (Ericsson, 2017), fez-se uma série de projeções positivas sobre as aplicações tecnológicas (o negócio da empresa patrocinadora da pesquisa) e o jornalismo. A pesquisa sugere que as tecnologias vão proporcionar o surgimento de novos empreendimentos, grandes e pequenos. Mas, de maneira resumida, ainda que explícita, é sugerido que muitos jornalistas serão substituídos por software:

Neste relatório, nós argumentamos que muitas das tarefas que são executadas por softwares de qualquer modo não o seriam sem computadores. Por exemplo, a mídia não tem condições de escrever relatórios de rendimentos a cada trimestre, e muitos jornais não podem contratar pesquisadores para 
cada tarefa que pode ser feita por um software em seus lugares.

Contudo, seria ingênuo acreditar que as empresas de mídia também não usarão tecnologia para cortar custos com a redução de pessoal. Nesse sentido, a inteligência artificial é tanto uma oportunidade para o jornalismo quanto uma ameaça para os jornalistas (Ericsson, 2017).

Segundo a Ericsson (2017), o Brasil (1.021 entrevistados) é o segundo país no mundo que vê positivamente o uso dos algoritmos na redação de notícias (63\%), logo depois da Coreia (81\%), seguido por Suécia (53\%) e EUA (47\%). A preocupação quanto a uma provável redução no número de postos de trabalho destinados aos jornalistas não aparece em outro relatório, divulgado no mesmo ano do levantamento da Ericsson. Elaborado pela The Associated Press (AP), o relatório The future of augmented journalism (2017), entre outras coisas, conclui que a inteligência artificial "nunca irá substituir o jornalismo. IA pode ajudar no processo de reportagens, mas jornalistas sempre serão necessários para reunir as peças e construir uma palatável, criativa narrativa" (Marconi, Siegman \& Machine Journalist, 2019). O relatório não se debruça, porém, sobre se o número de jornalistas seria o mesmo de antes da chegada da IA às redações. Prefere fixar-se mais nas possibilidades de manutenção do negócio em época de revolução digital e em meio à concorrência das plataformas de redes sociais.

"Esta é a era dos algoritmos de notícias", vaticina Diakopoulos (2019). Antes de citar o exemplo da AP, pioneira no uso de IA na geração de textos noticiosos mais simples, sem interferência humana direta. "Algoritmos não irão substituir humanos no atacado. Ao contrário, a era dos algoritmos de notícias diz respeito a projetar eficientes e efetivos sistemas que unam humanos e computadores (human-computer systems)" (pp. 1-2). Nessa mesma direção, Newman (2019), que conduz anualmente pesquisa com editores de empresas noticiosas de todo o mundo, informa que $78 \%$ deles pretendem investir em IA, mas $85 \%$ dizem preferir investir em jornalistas, apostando na mistura da inteligência humana com a máquina.

Tenhamos claro que essas previsões, positivas ou negativas, são cálculos probabilísticos daquilo que pode acontecer. As certezas cabem ao sempre mencionado futuro de algo. Por exemplo, se por um lado, há editores que garantem, como no caso da AP, que postos de trabalho não foram perdidos, também é certo considerar que novos profissionais não serão contratados para 
executar trabalhos agora feitos pela máquina. Por isso mesmo, aumentam os estudos apontando para o fim de profissões com a automação, incluindo a de jornalista (Frey \& Osborne, 2013), e outros informam a perda potencial de empregos com a automação. Só Brasil seriam 44,5 milhões de empregos ameaçados até 2040 (Neto \& Salgado, 2019). O jornalismo estaria assim tão afastado desse quadro?

Em outras palavras, não há riscos de haver uma redução de notícias por causa das mudanças no ambiente de mídia. O problema não é a geração de notícias, mas o futuro do jornalismo. Como Stephens (2014, p. xiii) coloca: "O futuro das notícias [...] parece razoavelmente seguro. É o futuro do jornalismo que parece cinza" (Hyvönen, 2018, p. 128).

\section{O problema e a solução do ensino}

Apesar dessas tensões, não é confortável afirmar que há um esforço coordenado, coerente e planejado no Brasil, nos setores público e privado, para se enfrentar os impactos da automação no mercado de trabalho em geral, e do jornalismo, em particular. Nesse último caso, como esperamos ter pontuado mais acima, há o risco concreto para o exercício da democracia, principalmente em função das fake news veiculadas nas mídias sociais (muitas com o beneplácito, quando não com o patrocínio, de governantes inescrupulosos) e dos ataques levados a cabo contra o jornalismo responsável (Newman, 2019), esteja sua prática a cargo da grande mídia ou não.

As práticas já bem documentadas de firehosing (Paul \& Matheus, 2016), iniciadas na Rússia, espalharam-se no Ocidente como estratégia publicitária por candidaturas político-partidárias que posteriormente foram timidamente questionadas pelo uso de fake news em seus canais formais de comunicação e nas suas redes sociais. As técnicas de desinformação são verificadas, entre outros métodos, pelo uso de publicidade em vários canais, variedade de "fontes", questionamento das falas especializadas, rapidez, continuidade e repetição de mentiras, descompromisso com relatos coerentes, despreocupação com a consistência da própria argumentação. E aqui nos ativemos apenas à política partidária propriamente dita. As fake news, potencializadas pela IA, penetraram de tal forma no ethos social que minam continuamente a credibilidade do jornalismo formal (idealmente, aquele com checagem, apegado 
aos dados e às fontes verificáveis, ético). E as fake news são apenas parte da estratégia de firehosing. Note-se aqui que o negócio jornalístico e o profissional jornalista (instâncias distintas) enfrentam duas crises simultâneas firmemente instaladas no futuro e no presente: a de credibilidade (e, portanto, de relevância social) e as das transformações na empresa jornalística a partir das novas possibilidades criadas pelas tecnologias emergentes de comunicação e informação.

A Universidade, e mais precisamente a docência em Jornalismo, parece-nos ter lugar de destaque justamente na intersecção dessa crise. Primeiramente, entender que todo o ensino formal está em mutação derivada dos avanços tecnológicos talvez seja algo recomendável para se ter como pano de fundo em uma reflexão ativa. A era digital, metamorfoseando-se no momento mesmo em que esse texto é escrito, exigiria, a rigor, uma mudança no aprendizado que começa nas escolas, nos níveis mais básicos. Essa mudança, em pleno desenvolvimento, precisa chamar a atenção dos agentes políticos da sociedade, que deveriam ser os promotores de políticas públicas que contemplem os movimentos de ação e reação às consequências do novo tempo. Mais do que aprendizado tecnológico, é preciso uma alfabetização social para a mídia, como propõe, por exemplo, Tomás Durán Becerra, pesquisador da União Europeia sobre educação midiática (Mattos, 2019). O problema é que a democracia e o mercado de trabalho não podem esperar por essa inevitável alteração no ensino formal e político da sociedade, que certamente virá. Mas novas abordagens precisam ser definidas já.

\section{O caminho interdisciplinar}

Pesquisadores distintos como Latour (2011), Sodré (2014) e Morin (2019) demonstram concordar que é salutar a volta da interdisciplinaridade para o efetivo entendimento do mundo contemporâneo em meio à crise da democracia. No ambiente corporativo, isso poderia ser entendido como "parcerias", uma entre tantas tentativas de sobrevivência e/ou reposicionamento no mercado. Como destaca o mencionado relatório da Associated Press (2019):

Inovadores por toda a indústria de notícias estão colaborando com empresas de tecnologia e pesquisadores acadêmicos para romper limites em áreas relacionadas, afetando todos os pontos da cadeia de valores da notícia, da sua coleta à produção e distribuição (Marconi, Siegman \& Machine Journalist, 2019, p. 1). 
Falando mais diretamente aos jornalistas e não apenas às empresas, iniciativas como as da Escola de Dados, que se define como uma rede global que auxilia jornalistas e cidadãos a tirar o máximo proveito de dados (posteriormente transformados em informação), caminham para entendimento similar ao da AP: "Entusiastas da computação estão, cada vez mais, se interessando pelo jornalismo e produzindo trabalhos e ferramentas importantes, mas é preciso que os jornalistas também se esforcem em diminuir o espaço que existe entre a computação e o jornalismo" (Escoladedados.org, 2019).

É nessa direção que parece seguir também a Associated Press ao se referir às habilidades que precisa ter o jornalista que pretende trabalhar em uma redação assistida por inteligência artificial: "Primeiro e mais importante é a disposição para colaborar. Jornalistas que trabalhem bem com cientistas de dados e jornalistas computacionais estão mais bem posicionados para serem bem-sucedidos em uma redação assistida por IA" (Marconi, Siegman \& Machine Journalist, 2019, p. 5).

De maneira crescente, mas pontual, esse esforço para facilitar a colaboração existente ou futura também tem sido feito por algumas universidades. Nos EUA, a North Western University tem se especializado no ensino de inovações digitais. A Columbia University é ainda mais "radical" ao levar adiante o curso de Jornalismo \& Ciência da Computação para pessoas com sólidos conhecimentos em matemática e letras. Graefe (2016), do Tow Center for Digital Journalism, propôs um guia para o jornalismo automatizado. Silverman (2013), do Centro de Jornalismo Europeu, editou um manual verificação para a era digital. Como uma maior aproximação com a Matemática é inevitável (e ao mesmo tempo mais do que desejável), pesquisadores (as) como Cohen (2013), insistem no uso dessa ciência nas redações: ela compilou conhecimentos essenciais para manipulações por jornalistas investigativos ou não.

Essas iniciativas têm um ponto em comum: reconhecem que as tradicionais ferramentas técnicas e teóricas para se pensar e fazer jornalismo não são mais suficientes para dar conta da complexidade contemporânea. Isso, de modo algum, quer dizer que tais ferramentas devam ser abandonadas, mas que precisam ser somadas a novos saberes. Esses saberes, aliás, não estão limitados pelos muros das universidades. A cibercultura permitiu a "expansão da palavra" (para o bem e para o mal) e a "inteligência coletiva", nas duas metáforas explicativas de Lemos \& Levy (2012). Empresas de jornalismo no Brasil e 
no mundo também têm promovido a interdisciplinaridade na composição de suas equipes. O relatório da AP sugere, por exemplo, os cinco subcampos da inteligência artificial que têm potencial jornalisticamente relevante: machine learning, linguagem natural (geração e processamento), discurso (discurso para texto e texto para discurso), visão (reconhecimento de imagem e visão computacional) e robótica (Marconi, Siegman \& Machine Journalist, 2019).

Empresas jornalísticas, como a já mencionada Associated Press, vêm investido em equipes que unem jornalistas, físicos e cientistas da computação, como sugerem ferramentas digitais criadas pelo The Washington Post, pelo The New York Times, pela BBC, pela The Economist, etc (Schmidt, 2017). No Brasil, as empresas jornalísticas que, enfim, sentem a pressão de alguma concorrência em seu mercado arcaicamente fechado, se esforçam para não serem atropeladas pelo aceleramento tecnológico e pelas inevitáveis novas relações no mercado de produção, consumo e circulação de notícias. Os profissionais do jornalismo têm os próprios e inéditos problemas, distintos daqueles dos empresários do setor. Por exemplo, desenvolver técnicas de questionamento à "imparcialidade" dos julgamentos dos algoritmos desenvolvidos para nos "auxiliar" a consumir notícias ou a direcionar nossa atenção nas redes sociais, como nas ocorrências verificadas no onipresente Facebook (Ali, Sapiezynski, Bogen, Korolova, Mislove \& Rieke, 2019). O premiado site de jornalismo investigativo ProPublica tem enfrentado a questão com estudo e técnica, como quando detectou as falhas no algoritmo usado no sistema judiciário norte-americano que discriminava quais presos deveriam ou não receber liberdade condicional (Angwin, Kirchner, Larson \& Mattu, 2016).

Assim, as trocas, acadêmicas ou não, ocorrem mais ou menos livremente, oriundas de fontes mais ou menos confiáveis.

\section{Conclusões propositivas}

Não pretendemos aqui detalhar o currículo de um curso de jornalismo computacional e de dados como fizeram com esmero Berret \& Phillips (2016) voltando-se para a realidade econômica, política, tecnológica e legal das universidades nos EUA. Nossa intenção é fazer proposições conceituais tendo como pano de fundo a atual movediça realidade brasileira que tem um governo central que deve se estender ao menos até 2022 (pois o Brasil adotou o estatuto da reeleição 
presidencial), avesso ao escrutínio jornalístico e à crítica acadêmica. As palavras de Hyvöen (2018) acerca dos ataques de Donald Trump à academia e ao jornalismo também valem para o Brasil desde janeiro de 2019 com a posse do presidente Jair Bolsonaro: "É fácil ver porque tantos consideram a presidência dele [Trump] como um repúdio a qualquer coisa que tanto jornalismo como o saber acadêmico representam: liberdade de expressão, perguntas transparentes, lógica, razão e busca da verdade" (p. 126). Ou, seja, para ser enfrentada, a crise que atravessa o jornalismo contemporâneo demanda coragem intelectual, disposição metodológica e análise política. É precisamente por isso que a questão tecnológica na profissão não pode ser abordada como um dado isolado, distante de toda influência político-ideológica.

Assim, gostaríamos de colocar em debate algumas diretrizes conceituais porque entendemos que estamos longe de um acordo curricular (embora a maioria concorde que mudanças precisam ser feitas com alguma urgência) o que demandaria um fórum de discussão mais amplo, principalmente tendo a graduação (e com ela novas gerações de jornalistas) como alvo central do debate, uma vez que são seus ingressantes os principais atingidos pela transição em curso do fazer jornalístico. Também é preciso envolver as empresas de comunicação (grandes, pequenas, nacionais e estrangeiras em exercício no país e de maneira equânime) na tomada de decisão acerca de suas necessidades, responsabilidades e possibilidade de colaboração, a exemplo de suas congêneres em países desenvolvidos. A participação das empresas é fundamental, principalmente em função da carência de aportes públicos e porque a crise também oferece oportunidades. A questão é saber quais empresas, em que velocidade e com quais resultados adaptar-se-ão mais rápido. Sociedade civil organizada e ONGs deveriam ser estimuladas a apresentar suas questões porque o desenvolvimento jornalístico envolve princípios fundamentais de sociedades que se dizem plenamente democráticas.

Isto posto, vamos dividir nossa sugestão de abordagem curricular em dois pontos: a) novas interdisciplinaridades e b) fortalecimento humanístico.

\subsection{Novas interdisciplinaridades}

O jornalismo é interdisciplinar por definição, ainda que a circunscrição de sua especificidade dentro do sempre em construção campo da comunicação tenha 
sido uma justa preocupação acadêmica, principalmente com a institucionalização das ciências sociais (Lopes, 2000-2001), ora largamente atacadas. Mas, certamente, este não é o momento de cerrar fileiras, mas de aproveitar a crise como uma oportunidade de cooperação conceitual com o aporte de saberes de novos campos. A crise do monopólio da autoridade jornalística, inquestionavelmente fraturado, se soma à da crise da autoridade científica, definida, por Bourdieu (1983), como capacidade técnica e poder social. Mas, se, como considera o autor francês, as práticas científicas não aparecem como desinteressadas, o Campo da Comunicação em geral e o jornalismo especificamente têm papel central nas transformações democráticas atuais. A crise possibilita, desse modo, o aumento da capacidade atrativa de outros campos do saber pela docência em Jornalismo.

A disciplina nasce atrelada às práticas sociológicas, matemáticas (teoria da matemática da comunicação, pesquisas de opinião etc), antropológicas, linguísticas, filosóficas, todas usadas também para o exercício teórico de circunscrição do campo. Agora, é preciso estabelecer parcerias com disciplinas ligadas às ciências exatas, em sentido acadêmico formal, como a Matemática, a Ciência da Computação (mais voltada para a construção de softwares, como os que podem se valer da inteligência artificial voltada para o exercício da profissão) e a Estatística. Os cursos de Jornalismo também deveriam atentar para a importância de seus alunos aprenderem minimamente rudimentos das principais linguagens de programação, principalmente das que conversam entre si.

Ao propormos o início do debate de alteração curricular nos cursos de jornalismo no país, temos consciência de que, em função da crise geral por que passam as universidades públicas, enfrentar uma mudança curricular desse tipo talvez (pelo menos, no Brasil) não pareça adequado nesse momento.

Contudo, os estudantes podem ser fortemente estimulados por seus professores a buscar cursos que preencham as lacunas técnicas que cada vez mais fortemente são identificadas pelo mercado. Por exemplo, o relatório da Associated Press já apresenta um sólido argumento da necessidade de compreensão da IA: "Inteligência artificial é complicada, e há muitas maneiras para ser implementada numa redação. Mas, exatamente como qualquer outra tecnologia, quanto mais você sabe sobre a ferramenta, mais efetivamente você pode usá-la" (Marconi, Siegman \& Machine Journalist, 2019, p. 19). 
Sugestão de diretriz: aproximação e fortalecimento de parcerias com os departamentos de Matemática e Ciência da Computação para a construção de um método de ensino que vença resistências cognitivas no processo de aprendizagem e passe a fazer sentido para os estudantes de Jornalismo. Da mesma forma, é importante a capacitação, no que couber, de professores dos departamentos de Jornalismo. Jornalistas precisam saber se comunicar com os profissionais de TI até para saber o que e como cobrar.

\subsection{Fortalecimento humanístico}

É importante salientar que nossa proposta de abordagem à crise de transição do jornalismo não é meramente instrumental, longe disso: mais acima, vimos que os algoritmos podem e devem ser questionados. Se por um lado, reafirmamos a importância do desenvolvimento de habilidades técnicas, exatas, elas não são suficientes para o questionamento crítico de suas consequências éticas e sociais. Algoritmos são criados por humanos e, assim como seus autores, produzem vieses. Confiar cegamente em softwares é desconsiderar o princípio fundamental da checagem e do uso de pluralidade de fontes na apresentação de fatos relevantes para a tomada de decisão social. Por outro lado, "o conhecimento comunicacional é indissociável da nova sensibilidade cotidiana, que emerge historicamente com as injunções culturais de todas as novas tecnologias" (Sodré, 2014, p. 178). Essa sensibilidade cibercultural é, assim, socialmente determinada.

Os adventos negativos recentes na política brasileira, que abusou do uso da tecnologia para fins diversos do alcance da verdade, mostram que a consciência crítica nas e sobre as redes sociais (mas não apenas nesses espaços) é extremamente imatura, mesmo entres profissionais de comunicação. O que vimos chamando aqui de transição do jornalismo "tradicional" para aquele atravessado pelas novas tecnologias emergentes exige, portanto, uma densidade crítica que depende fortemente de disciplinas das Ciências Humanas e Sociais Aplicadas, como Direito, Sociologia, Antropologia, Ética, Filosofia, Psicologia, entre outras.

No momento em que os jornalistas que se mantiverem nas redações e outros empreendimentos estiverem "liberados" pelas tecnologias para projetos mais amplos, deles será exigida maior capacidade de abstração social que possibi- 
lite trânsito teórico nos contextos em que os fatos se desenrolam. Essa exigência é mais rigorosa do que a que vigorava até meados dos anos 2000, antes da internet 2.0. Esses mesmos jornalistas também precisarão pensar criticamente sobre o modelo de comunicação arcaico, oligopolista, que vigora no país, e se vale à pena confrontá-lo, seja para o pleno exercício da pluralidade jornalística, seja em favor da representação dos cidadãos na esfera pública.

Sugestão de diretriz: aprofundamento das teorias explicadoras de Ciências Humanas e Sociais Aplicadas e o seu imbricamento transversal com a Ética, seja em sentido deontológico seja sem sentido amplo, que funcione como um crivo para os usos das tecnologias emergentes de comunicação.

\section{Referências}

Ali, M., Sapiezynski, P., Bogen, M., Korolova, A., Mislove, A. \& Rieke, A. (2019). Discrimination through optimization: how Facebook's ad delivery can lead to skewed outcomes. Recuperado de https://arxiv.org/ abs/1904.02095

Angwin, J., Kirchner, L., Larson, J. \& Mattu, S. (2016). How we analyzed the Compas recidivism algorithm. Recuperado de https://www.propublica.org/article/how-we-analyzed-the-compas-recidivism-algorithm

Bell, O. \& Owen, T. (2017). The Platform Press: How Silicon Valley reengineered journalism. Recuperado de https://www.cjr.org/tow_center_ reports/platform-press-how-silicon-valley-reengineered-journalism. php

Berret, C. \& Phillips, C. (2016). Teaching data e computational journalism. Nueva York: Columbia Journalism School, Knight Foundation.

Bordieu, P. (1983). O campo científico. En R. Ortiz (Ed.), Sociologia (pp. 122-55). São Paulo: Ática.

Briggs, A. \& Burke, P. (2006). Uma história social da mídia: de Gutemberg à Internet. Rio de Janeiro: Jorge Zahar Editor. 
Bucci, E. (2010). É possível fazer televisão pública no Brasil? Novos Estudos Cebrap, 88, 5-18.

Chomsky, N. (2017). Quem manda no mundo? São Paulo: Planeta.

Cohen, S. (2013). Numbers in the newsroom: using math and statistics in news. Recuperado de http://cvlassets.s3.amazonaws.com/Numbers in_the_Newsroom_Second_Edition.pdf

Comparato, F. (2010). Homens novos para um novo mundo. Recuperado de https://www.conversaafiada.com.br/brasil/2010/09/08/comparato-por-que-ir-ao-supremo-e-exigir-o-direito-de-se-comunicar

Dias, M. (2019). Pesquisa mostra que 83\% estão insatisfeitos com a democracia no Brasil. Recuperado de https://www1.folha.uol.com.br/mundo/2019/04/pesquisa-mostra-que-83-estao-insatisfeitos-com-democracia-no-brasil.shtml

Diakopoulos, N. (2019) Automating the News: How algorithms are rewriting the Media. Massachusetts: Harvard University Press.

Edelman (2019). Edelman Trust Barometer 2019. Recuperado de https:// www.edelman.com.br/estudos/trust-barometer-2019

Ericsson (2017). The Future of journalism in a networked society: Exploring potential new business models and smarter journalism for the digital era. Recuperado de https://www.ericsson.com/4a5427/assets/ local/trends-and-insights/networked-society-insights/the-future-ofjournalism-in-a-networked-society_screen.pdf

Escoladedados.org (2019). Raspagem e jornalismo de dados. Recuperado de https://escoladedados.org/tutoriais/raspagem-e-jornalismo-de-dados/

Fonseca, F. (2010). Mídia e poder: elementos conceituais e empíricos para o desenvolvimento da democracia brasileira. Brasília: IPEA. Recuperado de http://www.ipea.gov.br/portal/images/stories/PDFs/TDs/ td_1509.pdf 
Frey, C. \& Osborn, M. (2013). The future of employment: how susceptible are jobs to computerization? Recuperado de https://www.oxfordmartin. ox.ac.uk/downloads/academic/The_Future_of_Employment.pdf

Globo.com (2019). Europa aprova leis contra práticas desleais do Google. Recuperado de https://oglobo.globo.com/economia/europa-aprova-lei-contra-praticas-desleais-de-google-facebook-amazon-23606520

Graefe, A. (2016). Guide to automated journalism. Recuperado de https:// pdfs.semanticscholar.org/c56d/609b3cb2ff85a3e657d2614a6de45ad2d583.pdf

Greenwald, G. \& Neves, R. (2019). Vazamento seletivo. Recuperado de https://theintercept.com/2019/08/29/lava-jato-vazamentos-imprensa/

Greenwald, G., Reed, B. \& Demori, L. (2019). Como e por que o intercept está publicando chats privados sobre a Lava Jato e Sergio Moro. Recuperado de https://theintercept.com/2019/06/09/editorial-chats-telegram-lava-jato-moro/

Haddad, F. (2017). Vivi na pele o que aprendi nos livros: um encontro com o patrimonialismo brasileiro. Recuperado de https://piaui.folha.uol. com.br/materia/vivi-na-pele-o-que-aprendi-nos-livros/

Hyvönen, M. (2018). As a matter of fact: journalism and scholarship in the post-truth era. En M. Peters, S. Rider, M. Hyvöen \& T. Besley (Eds.), Post-truth, fake news: Viral modernity \& higher education. Recuperado de https://www.springer.com/gp/book/9789811080128

Latour, B. (2011). A ciência em ação: como seguir cientistas e engenheiros sociedade afora. São Paulo: Unesp.

Lemos, A. \& Lévy, P. (2012). O futuro da Internet: em direção a uma cibercultura planetária. São Paulo: Paulus.

Lima, V. (2012). Liberdade de expressão X liberdade de imprensa: direito à comunicação e democracia. São Paulo: Publisher 
Lopes, I. (2000). O campo da comunicação: reflexão sobre seu estatuto disciplinar. Revista da USP. 48, 46-57. Recuperado de http://www.revistas.usp.br/revusp/article/view/32890/35460

Marconi, F., Siegman, A. \& Machine Journalist (2019). The Future of augmented journalism: A guide for newsrooms in the age of smart machines. Recuperado de https://insights.ap.org/uploads/images/the-future-of-augmented-journalism_ap-report.pdf

Mattos, L. (2019). Contra fake news, sociedade tem que ser alfabetizada para a midia, diz pesquisador. Recuperado de https://www1.folha. uol.com.br/educacao/2019/08/contra-fake-news-sociedade-tem-que-ser-alfabetizada-para-a-midia-diz-pesquisador.shtml

Mauersberger, C. (2016). Advocacy Coalitions: Democratizing Media Reforms in Latin America - Whose Voices Gets on Air? Berlín: Springer, Free University of Berlin.

Neto, J. \& Salgado, E. (2019). Automação ameaça metade dos empregos no país. Saiba as profissões que podem ser afetadas pela tecnologia. Recuperado de https://oglobo.globo.com/economia/automacao-ameaca-metade-dos-empregos-no-pais-saiba-as-profissoes-que-podem-ser-afetadas-pela-tecnologia-23886095

Newman, N. (2019). Journalism, media and technology. Trends and predictions. Recuperado de https://reutersinstitute.politics.ox.ac.uk/ our-research/journalism-media-and-technology-trends-and-predictions-2019

Passos, U. (2019). Seguimos como sonâmbulos estamos indo rumo ao desastre, diz Edgar Morin. Recuperado de https://www1.folha.uol.com. br/mundo/2019/06/seguimos-como-sonambulos-e-estamos-indo-rumo-ao-desastre-diz-edgar-morin.shtml

Paul, C. \& Mathews, M. (2016). The Russian "firehose o falsehood" propaganda model: why it might work and options to counter it. Recuperado de https://www.rand.org/pubs/perspectives/PE198.html 
Proner, C. \& Strozake, N. (2017). Frente Brasil de juristas pela democracia em defesa do devido processo legal. En Proner, C., Cittadino, G., Ricobom, G. \& Dornelles, J. (Orgs.), Comentários a uma sentença aunciada: O processo Lula (pp. 14-16). Recuperado de http://biblioteca. clacso.edu.ar/clacso/se/20180110032136/Comentarios_a_uma_Sentenca_Anunciada.pdf

Rydlewski, C. (2019). Inteligência artificial garante potencial destrutivo às "deepfakes", nova categoria de "fake news". Recuperado de https:// www.valor.com.br/cultura/6272493/inteligencia-artificial-garante-potencial-destrutivo-deepfakes-nova-categoria-das-fake-news

Schmidt, T. (2017). Jornalismo inteligente: inteligência artificial nas redações. Recuperado de https://pt.ejo.ch/jornalismo/jornalismo-inteligente-inteligencia-artificial-nas-redacoes

Silverman, G. (2013). Manual de verificação: um guia definitivo para verificação de conteúdo digital na cobertura de emergências. Recuperado de http://verificationhandbook.com/downloads/manual.de.verificacao.pdf

Sodré, M. (2014). A ciência do comum: notas para o método comunicacional. Petrópolis: Vozes.

Souza, J. (2017). A elite do atraso: da escravidão à Lava a Jato. São Paulo: Leya.

UOL (2018). Facebook registra lucro líquido de US\$ 15,9 bilhões em 2017, alta de 56\%. Recuperado de https:/economia.uol.com.br/noticias/ efe/2018/01/31/facebook-registra-lucro-liquido-de-us-159-bilhoes-em-2017-alta-de-56.htm

Werneck Sodré, N. (1994). História da Imprensa no Brasil. São Paulo: Mauad. 